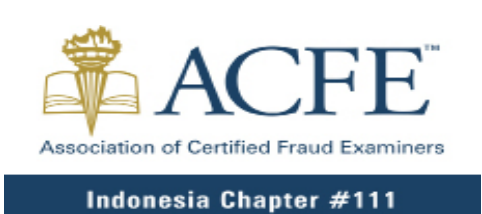

Asia Pacific Fraud Journal

E-ISSN: 2502-695X, ISSN: 2502-8731

Volume 4, Nomor 2 (July-December) 2019

http://apfjournal.or.id/index.php/apf

\title{
RESTORING THE CAPACITY OF LEADERSHIP AS ROLE MODEL TO BUILD ANTI FRAUD CULTURE AND SYSTEM: A STUDY OF INDONESIA
}

\author{
ARTICLE INFORMATION \\ Article History: \\ Received May 30, 2018 \\ Revised Jan 01, 2019 \\ Accepted May 20, 2019 \\ JEL Classifications: \\ D73; M14; O21 \\ DOI: \\ 10.21532/apfjournal.v4i2.112
}

\author{
Esther Roseline
}

\section{INTRODUCTION}

The devastating global scourge of fraud poses a persistent challenge and an enormous threat to all kinds of organizations, regardless of the sizes and types. As the globalization of finance

\begin{abstract}
ABTRACT
Fraud poses an enormous threat to all kinds of organizations worldwide, with its risks continue to increase in number and complexity. In Indonesia itself, rampant fraud and corruption still inflict our business climate and impede our national development ruthlessly. As the battle against fraud is evolving, the role of leadership is widely recognized as the crucial element in fraud management framework. Nonetheless, as much as many people's trust towards leaders' integrity seems to atrophy, whether leadership is still able to make a difference remains a big question mark. With its capacity crippled by a vicious cycle of fraud, the scope of leadership may be severely limited even if it were possible. For this reason, it is important to realize that the capacity of leadership needs to be restored in order to become role model in building anti-fraud culture and system. Therefore, the purpose of this paper is to explore accounts of leadership, identify the impact of leadership on anti-fraud culture and system, describe the way fraud works in undermining the capacity of leadership, and finally to elaborate the solutions to restore the capacity of leadership as role model to build antifraud culture and system in an organization. To achieve these goals, the author delves into various literature, journals, books, reports, applicable laws and general principles of law, as well as conducts an empirical research through a survey. The survey was conducted with 358 respondents, of which the 142 are Indonesian citizen working in public sector, and 216 in private sector. Focusing on Indonesia, this research paper will reveal the current public perception towards leadership, unfold the real condition of leadership, discover an existing vicious cycle of fraud that entraps leaders, and proffer strategy to solve this problematic leadership issue.
\end{abstract}

increases, so is the proliferation of Address opportunities for fraud. All organizations are subject to fraud risks which are impossible to be eliminated but "continue to grow in number and complexity." On the other hand, fraud is among the most

Email : estheroselines@gmail.com

Association of Certified Fraud Examiners (ACFE) Indonesia Chapter (C) 2019 
costly of all criminal activities. While the amount of acute damage due to fraud is incredibly large and too much is at stake, a study shows that the majority of the victims have recovered nothing. Annually, it is estimated that organizations typically lose $5 \%$ of their revenues to fraud, and which if applied to the 2017 estimated Gross World Product (USD 79.6 trillion), the estimated total global fraud loss isprojected to be USD 4 trillion. The total losses caused by the 2,690 cases recently studied by Association of Certified Fraud Examiners in 2018 exceeded USD 7.1 billion. Nonetheless, this amount is still a tiny fraction of the true global cost of fraud. In addition to the real greater number of fraud occurrences worldwide, indirect costs which are equally devastating such as harmed reputation and loss of business have not been factored in. For this reason, the accurate total cost of fraud is impossible to be calculated, yet its unquantifiable harmful impact to economy and society is undeniable. As organizations are making tremendous strides in combating fraud, the battle against fraud worldwide is constantly evolving.

In Indonesia, fraud and corruption epidemic continues to acutely inflictour business climate, distort competition, and impede social and economic development. Fraud rate in Indonesia is considered the highest among Asia Pacific, which is of as much as $5 \%$ of the total Gross Merchandise Value (GMV). The percentage of consumers that have experienced fraud at least once in 2017 is $49.8 \%$ - exceeding the Asia Pacific average, and consumers encountered most incidents in Financial Services fraud. Additionally, the Digital Trust Index of Indonesia is the lowest among Asia Pacific Industry, that is,2.90 (with 0 is no trust and 10 is very high trust). In banking sector, Deposit Insurance Agency admitted that from 2015 to 2017, 81 banks have been liquidated, and most of them are due to fraud committed by the owner or the management. Furthermore, despite seemingly various means exhausted to prevent and eradicate corruption in
Indonesia, Indonesia still scored poorly in Transparency International Corruption Perceptions Index (CPI) 2017: 37 out of 100 (with 0 being highly corrupt), without any improvement from the 2016 result. Fraud and corrupt practices continue to grease the nation's economic activity. Nevertheless, as much as this bleak situation seems to persist, the yearning to put an end to this evil phenomenon never ceases.

Although absolute elimination of risks of economic crime is most likely unattainable, minimisation of the risks to a great extent and creation of a strong fraud deterrence effect is entirely feasible. In fact, a failure to exhaust every means to manage and respond to fraud risks may cause organization "die an immediate death" or "run the risk of eventual extinction." On the other hand, there has been an abundant evidence that tightly links good ethics with good business. Therefore, effective fraud prevention, a timely fraud detection and effective response mechanisms, are supremely imperative in safeguarding organizations' interests against fraud's negative impacts. Nonetheless, the big question of how to do it is not a trivial issue to tackle.

Enhancing and establishing an ethical, anti-fraud culture and system, has been widely suggested as 'fundamental to fraud mitigation,' the 'key to effective fraud mitigation,' and' a strong fraud prevention program,' This proposition is not without basis. Organizational culture or climate for ethicscan generally be defined as the "organizational members' shared perceptions of what is ethically correct behavior and how ethical issues should be handled." In other words, the condition of an ethical and anti-fraud culture/ climate is the predictor of the existence of unethical and corrupt conduct. It is through the deployment of an effective anti-fraud system that the creation of anti-fraud cultureis attempted to be achieved, which is usually done through fraud awareness initiatives and anti-fraud training. For this reason, leadership and commitment of the executive head and the 
senior management is essential to create an anti-fraud culture in an organization since there must be a strong will from the top for an effective anti-fraud system to be implemented in an organization. Many anti-fraud programmes failed due to lack of political will and commitment from the top. Nonetheless, an inevitable question then demands an answer: will an antifraud system and programmes be able to operate successfully in an organization rife with fraud, corrupt practices, and pluralistic ignorance?

The significance of leadership in creating an anti-fraud system and antifraud culturein an organization is beyond doubt. However, whether leadersstill possess the adequate capacity of leadership to execute the important anti-fraud role is unfortunately dubious. In this paper, the author, focusing on Indonesia, will address the problematic existence of a vicious fraud cycle that has destroyed many leadership roles in organizations. The author will start by exploring the fundamental principles of the role of leaders, continue by discussing the vicious cycle of fraud, and conclude with a solution of how to restore the capacity of leadership as role model to build anti-fraud system and culture.

\section{Formulation of Issues}

Based on the background, the issues that need to be discussed are, as follows:

1. What is leadership?

2. What is the impact of leadershipon anti-fraud culture and system?

3. How does fraud work in undermining the capacity of leadership in becoming role model to build anti-fraud culture and system?

4. How to restore the capacity of leadership as role model to build antifraud culture and system?

\section{Purposes of Paper}

In writing this paper, the author proposes the following purposes in the above formulation of issues:

1. To explore the accounts of leadership

2. To identify the impact of leadership on anti-fraud culture and system
3. To describe the way fraud works in undermining the capacity of leadership in becoming role model to build antifraud culture and system

4. To elaborate the solutions of restoring the capacity of leadership as role model to build anti-fraud culture and system.

\section{RESEARCH RESULT DISCUSSION}

AND

\section{Leadership Literature Review}

The term 'leadership' sufferswhat scholars call a problematic 'definition question. Although leadership is an age-old concept, enormous amount of leadership literature has become no nearer a consensus as to its basic meaning. There are nearly as many definitions of leadership as there are researchers and commentators. The most traditional definition of leadership takes a positional approach which defines leadership as "activity undertaken by someone whose position on a vertical, and usually formal, hierarchy provides them with the resources to lead." Hence the 'trait' of the leader is less relevant than the 'position.' However, another account of leadership, rejecting the positional approach, takes an Aristotelian model which describes leadership as a 'master virtue,'incorporating many other virtues, whose ends are subsumed under the preferred ends which aim at the ultimate good for humans-human flourishing:

Leadership that is pursued either as an end in itself, or that fails to integrate itself properly with other virtues, or that fails to subordinate its ends to the larger ends for which it should be pursued - whether by failing to identify those larger preferable ends or for ulterior reasons, is not real leadership. It is leadership gone awry.

Besides Aristotelian model of leadership is Burns' account of 'transforming leadership' which occurs when 'leaders and followers raise one another to higher levels of morality.' As Ciulla notes:

Transforming leaders have very strong values. They do not water down their values and moral ideas by consensus, but rather they elevate people using conflict to 
engage followers and help them reassess their own values and needs.

Transformational elements are conceptualized by the four I's (Individualized consideration, Idealized influence, Intellectual stimulation, and Inspirational motivation), in which followers perceive personalized support, a role model whom they can trust, a sense of vision, and stimulation to change as needed. Another leadership account is 'instrumental leadership' which characterizes leaders who offer their followers guidance and directions for job completion. Under this account, ethical leadership is a value-driven form of leadership which influences the self-concept and beliefs of their followers and ultimately their work output and focus on organization's good rather than their own.

Most debates on leadership, nevertheless, revolve around two principal issues of leadership: (1) to what degreeleaders, through their exercise of leadership, possess the ability to makeimpact over their subordinates (influence or sole power?) (2) whether leadership qua role (or position) is segregated from the quality of leadership. These two issuesinvoke two important questions:How much of an influence canleadership have on an organization? What underlies the issue of segregationbetween the office or position of leadership and quality of leadership, while they are supposed to be one and the same?

\section{Impact of Leadership on Anti-Fraud System and Culture}

In an organization, the prevention and detection of and response to fraud constitute one of the primary and critical responsibilities of top management, and the imperativeness for the executive heads to set a clear, unambiguous and sufficiently strong "tone" throughout the organization is unquestionable. Business leaders' behaviour becomes the critical determinant of an ethical climate in organizations. Research has shown that although in large organizations senior managers are far removed from most employees, thus hardly able to become role models to provide explicit behavior to mimic, top managers still play an important role in shaping the ethical culture, and have both direct and indirect effects on employeeattitudes and behaviors. Additionally, the effectiveness of guideliness on ethical behaviour norms and robust anti-fraud programme requires a strong commitment from senior leadership to develop and put into practice.

Path-goal theory posits that management is responsible for setting clear goals, clarifying paths to achieve goals, and implementing reward systems contingent on achieving expected performance. Consistent with this theory is a proposition that leadership, reward systems, perceived fairness, ethics as a topic of conversation in the organization, employee authority structures and an organizational focus that communicates care for employees and the community" are some elements of ethical climate and culture. Managerial decision plays an undeniably crucial role in setting clear ethical standards that reflect theethical character of organization, communicating ethical expectations, disciplining unethical acts, and implementing appropriate reward systems to encourage compliance with task guidelines and norms. These kinds of decisions greatly affect the employee's trust towards the management and confidence that the management will behave ethically, thus enhancing their satisfaction with the supervisor as well as their job satisfaction, whichlater maximize their job performance in achieving group goals, and diminish dysfunctional activity.

A survey I made with 358 respondents (consist of Indonesian citizens above 17 years old that have worked or have been working in Indonesia for the past 3-5 years) provides a corroborative result. When asked about how confident they are that the integrity, honesty, and ethics of a Leader will influence thesubordinates, a big majority of $76 \%$ chose "Very Confident" (comprises 71.1\% of 142 respondents working in the public sector, and $79.6 \%$ of 216 respondents working 
in the private sector).Additionally, when asked whether the characters or traits of their Leader (both the positive and negative) have affected them personally, again $67 \%$ of the respondents chose "Yes (have been affected)" (comprises 64.8\% of 142 respondents working in the public sector, and $69 \%$ of 216 respondents working in the private sector). This survey result clearly substantiates one fact: that theprofound impact a leader can make towards an organization and its people, is no trivial matter.

The crucial role that the top management plays in building antifraud system and culture has recently been strongly recognized by Indonesian Supreme Court through the ratification of Supreme Court Regulation No. 13 Year 2016 on Procedures for Handling Corporate Criminal Cases. Article 4 of the Regulation stipulated that corporations may be subject to criminal liability in accordance to the Corporate criminal provisions in the law governing Corporation. Corporation'sguilt shall be assesed by the Judge based on the following criteria: (1) Corporation may acquire profits or benefits from such criminal acts or such criminal acts are comitted in the interest of the Corporation; (2) Corporation permits or condones or tolerates such criminal offenses; or (3) Corporation fails to take necessary steps to conduct prevention, to prevent greater impact, and to ensure compliance with the prevailing laws and regulations in order to avoid the occurrence of criminal acts. The enactment of Supreme Court Regulation No. 13/2016 was truly the first step of a laudable breakthrough, to prevent companies from exonerating themselves andto prohibit management from insulating themselves from blame for allowing criminal acts to thrive within the organization.

In a democracy setting where the government is said to be of the people, by the people, and for the people, the vertical leadership role is not transferred to the people but still retained by the ruling political leaders/representatives that have supposedly gained public trustand popular acclamation through election. These ruling authorities manage democracies with the consent of the managed population. The citizen participation enshrined in a democratic political system only encourages a shared leadership setting where the vertical leadership is expected to cooperate with the team members, reflecting a situation that is characterized by collaborative decision-making and shared responsibility for outcomes. Such concept is also reflected in Indonesian 1945 Constitutional Law where it is stated that although Sovereignty rests on the hands of people, the President holds the Governmental Power in accordance to the Constitutional Law. In a broader sense, the governmental power also includes and is separated into the executive, judicative, and legislative power. Consequently, the idea of top-down effect of leadership is still applicableeven in a democratic system.

Having identified the crucial role of leadership on ethical climate and system, we are yet to be confronted with one troubling issue: have these accounts on the significant effects of leadership been too optimistic? Bums $(1978,265)$, seems to plunge all our accounts into fantasy when he tells acynical story of a French-man sitting in a cafe who hears a disturbance, runs to the window, and cries: "There goes the mob. I am their leader. I must follow them!" Some of the best practical writers do caution that leaders' effects are only modest due to the great constraints and the inertia they have to face, and even if leadership were possible, its scope may be severely limited.The idea that leadership also requires a reasonably ethical environment in order to operate at all hence begins to gain force. Limiting ethics to only refer to 'anti-fraud,' this links us to our core issue: Has fraud usurped and undercut the leadership power - acutely divorcing the 'job' or role of leadership from the true quality of leadership? 
The Undermining Power of Vicious Cycle of Fraud towards Leadership

There is a very famous saying by Lord Acton that says, "Power tends to corrupt and absolute power corrupts absolutely. Great men are almost always bad men, even when they exercise influence and not authority; still more when you superadd the tendency of the certainty of corruption by authority." The idea of corrupt absolute powerbecomes the major reason for the shift of authoritarian regime intothe emergenceof democracy, separation of powers, and decentralization in political concept. Unfortunately, John Adams furthercommented on the development of democracy: "My opinion is, and always has been, that absolute power intoxicates alike despots, monarchs, aristocrats, and democrats, and jacobins, and sans culottes." Democracy's failure to curb corruption and decentralization's achievement in decentralizing corruption seem to support John Adams' statement. These should ring us a bell of how broken the role of leaders has appeared in the eyes of people, and how the bitter segregation between the role/position of leadership and quality of leadership has become so embedded in our society's belief.

A wave of distrust towards leaders' integrity turns out to be prevalent in both public and private sectors throughout the country. The prominent case of E-KTP (electronic identity card) corruption that dragged the Chairman of the Parliament (Dewan Perwakilan Rakyat), Setya Novanto, into court has recently become one of the major reasons the public begin to view the Parliament as the most corrupt institution. In the survey I made with the same 358 respondents mentioned in the previous section, only $31.8 \%$ confirmed they absolutely trust that their leaders are honest and with integrity (comprising $26.1 \%$ of 142 respondents working in the public sector, and $35.6 \%$ of 216 respondents working in the private sector). The remaining are either doubtful $(60.5 \%$ in public sector, $58.4 \%$ in private sector)or do not trust at all (13.4\% in public sector, $6 \%$ in private sector).This pernicious existence of ongoing scant trust towards leadersis indeed a serious matter. Nonetheless, does fraud really start only from the top and cascade to the low levels? Is it possible that things go the other way around - that is, fraud develops at the bottom and escalates to the top like a poisonous gas?

Those who hold the substantial positions of leadership should not be the ones bearing all the blame. Leaders never act in a vacuum - they are 'a part of the flow of history and set in a culture. Although leaders canenable and perpetuate ethical behaviors to allow self-perpetuating and amplifying effects experienced by the members of the organization, leaders can also be trapped in a vicious cycle of fraud. This cycle is what has stripped leaders in top positions of their capacity and true quality of leadership.

To understand this vicious cycle, we may first start from a countrywide point of view, where those taking high governmental positions are the leaders. Despite our vigorous censure on corruption done by public officials, we cannot shut our eyes to the fact that the private sector actually plays a highly active role in corruption, and has become the main cause of corruption as well. Additionally, instead of asking "why are they corrupt leaders?" we should ask the question of "how did they become leaders in the first place and what shaped their behaviors?" As much as we know that money politics has been burdening our general elections, surveys suggest that money politics actually happened also due tothe request or expectation formoney and/or some forms of benefits from the people themselves. Ironically, after the enactment of the new Law No. 10 Year 2016 on the Second Amendment of Law No. 1 Year 2015 ("Regional Head Election Law")which penalizes both the giver and the recipientin an event of vote buying/ money politics, the number of reported money politics cases in 2017 Regional Head Election even increased considerably compared to the 2015. Moving our view 
into smaller units, within governmental institutions themselves Indonesia has recently been staggered by the unfolding of myriad illegal sale and purchaseof position cases ("jual beli jabatan") which turn out to have long been embedded in public offices, even to the lower levels. While from the top position point of view the high cost of politics is what triggers this corrupt practice, yet from the lower level point of view, this illegal sale and purchase of position that has been considered as "a usual requirement" everybody is willing to comply with is what hikes the cost of politics itself. It turns out, however, that this culture is also developing in private sector as well.The survey with the same former 358 respondents (142 in public; 216 in private), gave an astonishing result. When asked whether the illegal sale and purchase of position practice is rampant in their workplace, surprisingly only $21.8 \%$ in public sector answered yes, and also surprisingly at least $8.3 \%$ in private sector answered yes. While the existence of $8.3 \%$ in private sector is quite unexpected, the number of $21.8 \%$ "yes" answers in public sector is much smaller than expected. Is it true that the sale and purchase of position practice is not as rampant as presumed to be? To answer this, a more indirect question is asked to the same respondents: whether in the work environment where you are working or have worked, a culture or common understanding has been formed that to maintain a position or receive a quick/easy promotion, some degree of 'influence' or "money" is necessary, in the form of "collusion", "conspiracy", or the like. The percentage suddenly escalates: $43 \%$ in public sector answered "yes" and "slightly," while $29.6 \%$ in private sector answered "yes," "slightly," and added the options of "nepotism" and "closeness with the supervisor."The first question points out about factual occurrences, while the second question signifies a perception. Hence, there are two possible inferences arising from the result: (1) the rampant illegal sale and purchase of position practice is just perceived to be existing by people, but not real; or (2) it is real, but people do not admit it due to its massiveness that leads to rationalization and normalization, and/or that in the first question, many respondents would have to face the reality of reporting on their own behavior - which means, this again suggests the massiveness of the practice. The second possible inference, however, is consistent with the law enforcers' complaint of difficulty in taking action against the perpetrators due to lack of witnesses and scarce number of people who would officially report the occurrences. Regardless of whether the first or second inference is the correct one, a self-fulfilling prophecy is possible to have occurred, and which makes both of the possible inferences become actually true. On one hand, the fact that at least one case of illegal sale and purchase of position hasrecently been proven in court implies that such prevalent corrupt practices do exist. On the other hand, even if the prevalence is just perceived, this widely perceived culture is undoubtedly powerful enough to create an actual reality just like how it is perceived due to the mindset of "everybody is doing it" - againleads to the same rationalization and normalization. This signifies a scary truth: those who go up to reach substantial positions are those who have gotten along with the corrupt culture.

The preceding paragraph has elaborated howa vicious cycle of fraud exists - that is, fraud culture develops from the bottom as much as it does from the top. How can we expect those holding leadership positions to build an anti-fraud culture and system, when the vice versa is all he ever cognizes and/or what the organization he is leading ever apprehends?

\section{Restoring the Capacity and Role of Leadership for Anti-Fraud System and Culture}

The only way to make possible a wellfunctioned leadership that can effectively build an anti-fraud system and culture is to restore its impaired and crippled capacity and role. The restoration process, however, 
is astrenuous task to do, entailing sweat from both the leader and the members.

The first key is trust; labelling a leader as dishonest is tantamount to incapacitating the leader from actually upholding integrity. Sense of distrust against leaders should be minimized if elimination is not possible. To encourage this trust, enhancing transparency between leaders and members becomes a crucial element. The next step is to bolster up and popularize examples of "The Ethical Majority"-those who uphold integrityand those who perform without fraud. By doing this, we will stop amplifying the number of unethical people, muting the widely perceived ethical crisis, thus putting a halt to a cycle of self-fulfilling prophecy, and then start promoting a new encouraging positive perspective of "you are not the only ethical people left." The third step is to build a sense of leadership among the members, creating a model of healthy shared leadership. This shared leadership model will empower the members to uphold integrity regardless of how corrupt the existing leaders above them. This empowerment will thrust ethical culture into every structure of organization, including the top management. Simultaneously, the leaders holding substantial positions should begin to courageously and effectively impose anti-fraud system and culture, and continuously communicate anti-fraud conduct to the subordinates, regardless of what the popular culture is. In fact, an ideal shared leadership model which consists of Vertical Transformational, Empowering Leadership and Team Member Integrity will achieve positive organizational results and develop a climate of innovation that substantially supports for higher levels of performance. The legal mechanism and enforcement should be supportive of this model as well; that is, corrupt behaviours and bribery in both public and private sector should be strictly and fairly acted upon, especially pursuant to the implementation of the ratified United Nations Convention Against Corruption.
Without taking the above three steps as the initial efforts to breakthe existing vicious cycle of fraud, any mechanisms put in place to maximize the role of leadership in setting anti-fraud culture and system, will be of little to no avail.

\section{CONCLUSION}

The heated debates on "definition question" issue suffered by the term 'leadership'mostly revolve around two principalissues: (1) to what degree leaders, through their exercise of leadership, possess the ability to make impact over their subordinates (influence or sole power?) (2) whether leadership qua role (or position) is segregated from the quality of leadership. It is widely recognized that the prevention and detection of and response to fraud are the primary and critical responsibilities of top management. It is supremely important for the executive heads to set a clear, unambiguous and sufficiently strong "tone" throughout the organization. The top-down effect of leadership does play a crucial role in building anti-fraud culture and system. Unfortunately, whether leaders can actually make a difference in reality becomes a dubious issue due to an undesirable segregation between position of leadership and quality of leadership, which is caused by a vicious cycle of fraud.

The vicious cycle of fraud takes an inexorable life of its own when fraud develops from the bottom as much as it does from the top. Leaders are trapped in this cycle of fraud and become unable to operate ethically in an unethical environment.These great constraints on leaders reduce significantly the effects of leaders, and even if leadership were possible, its scope may be severely limited. It is of paramount importance that those holding leadership positions must be able to regain its rightful capacity again in order to set up an anti-fraud culture and system in organizations.

There are three essential steps to restore the capacity and quality of leadership to be able to build an anti-fraud system and climate. First is reviving trust towards 
leaders. Second, the popularization of real life stories on people who are honest and of high integrity should start to outweigh the high exposure of negative reports on fraud and corrupt practices. Third, through a model of shared leadership, simultaneous anti-fraud actions and commitment by both the leaders and members in every organizational unit should commence without waiting for "who should start first."

As much as leadership plays a crucial role in building anti-fraud culture and system, leadership also possesses the worst danger in building a fraud culture and system, yet it is most of the times powerless in the face of a wheeling vicious cycle of fraud. It takes a lot of conscious effort to discontinue the fraud cycle and start unleashing a virtuous cycle of antifraudwhich constitutes effective fraud prevention, a timely fraud detection, and effective response mechanisms. Although it is not impossible, its success extremely depends on the commitment of every stakeholder - that is, the commitment to pay the highest price for the best outcome, and the price is not always monetary. It has to be understood that difficult things are most possible when the will to attain it is the strongest. 